\title{
1. Strategic entrepreneurship research: an introduction
}

\author{
Vishal K. Gupta, A. Banu Goktan, Galina V. \\ Shirokova, and Amit Karna
}

Organizational researchers have long been interested in the links between strategy and entrepreneurship (Acs \& Audtretsch, 2003; Bruton, Filatotchev, Si, \& Wright, 2013; Ireland, 2007). For many, strategy and entrepreneurship are two sides of the "economic value" coin, with entrepreneurship researchers delving into value creation and strategy researchers generally gravitating towards value capture (Lepak, Smith, \& Taylor, 2007; Pitelis, 2009). Drawing upon Shakespeare's famous play Romeo and Juliet, Venkataraman and Sarasvathy (2001) likened entrepreneurship research without a strategic perspective to Romeo without a balcony, and strategy research absent the entrepreneur to the balcony without Romeo. ${ }^{1}$ Schendel and Hofer (1979: 6) argued that, the "entrepreneurial choice is at the heart of the concept of strategy." In a similar fashion, strategic thinking is seen as an entrepreneurial imperative (Zabriskie \& Huellmantel, 1991).

Given the close affinity between strategy and entrepreneurship research, it is not surprising that there is a significant overlap between the membership of the Academy of Management's entrepreneurship and strategy divisions. For about 50 percent of the members of the entrepreneurship division, their other affiliation is with the strategy division (and vice versa). The close links between entrepreneurship and strategy do not always go down well with scholars (Alvarez \& Barney, 2001; Kraus $\&$ Kauranen, 2009; Shane, 2012). Some are concerned about strategy's "takeover of the academic field of entrepreneurship" (Baker \& Pollock, 2007: 237). For others, there is a real risk - perhaps, even fear - that entrepreneurship may overshadow or overwhelm strategy research (Gupta, 2020). Consider that when entrepreneurship became an independent division of the Academy of Management in 1987, it was originally considered a "spin-off" of the strategy division (Kraus \& Kauranen, 2009). At the Strategic Management Society, which is the premier "professional association devoted exclusively to the study of strategic management" (Hambrick \& Chen, 2008: 44), the entrepreneurship track now attracts the most submissions, far outpacing the many traditional tracks of strategy research. As a result of this tension between the two fields, there is growing talk about "strategy vs. entrepreneurship" (Meyer, 2009: 346 ), as if the two fields are competing in a zero-sum game where the survival and growth of one field (and scholars in that field) will come at the expense of the other field.

It was in this zeitgeist - one where strategy and entrepreneurship research came to be seen as rivals, competing for scarce resources and critical legitimacy - that 
the phrase "strategic entrepreneurship" (SE) was introduced (Kuratko \& Audretsch, 2009). Emphasizing the need to explore the intersection of strategic thinking and entrepreneurial mindset, Hitt, Ireland, Camp, \& Sexton (2001: 481) define SE as the "integration of entrepreneurial (i.e., opportunity-seeking behavior) and strategic (i.e., advantage-seeking) perspectives in developing and taking actions designed to create wealth." Both strategy and entrepreneurship scholars were interested in understanding how economic actors create and sustain a competitive advantage (Alvarez \& Busenitz, 2001). As such, SE was seen as dealing with the combination of "effective opportunity-seeking behavior (i.e., entrepreneurship) with effective advantage-seeking behavior (i.e., strategic management)" (Ireland, Hitt, \& Sirmon, 2003: 964). In effect, SE combined the strategic logic of competitive advantage with the entrepreneurial logic of opportunity creation and discovery.

Hitt et al. (2001: 13) introduced the then "new concept (of) strategic entrepreneurship" through an edited book that brought together strategic management and entrepreneurship literatures. Since then, research around SE quickly proliferated, and SE began to be described as an academic field in its own right (Foss \& Lyngsie, 2011). Moreover, SE - much like strategy and entrepreneurship research - came to have a scattered and fragmented literature with contributions from scholars across multiple disciplines such as "economics, psychology, sociology, along with other sub disciplines in management including organizational behavior and organization theory" (Hitt, Ireland, Sirmon, \& Trahms, 2011: 57).

In 2007, the launch of the Strategic Entrepreneurship Journal was a major step that helped the formation, and subsequent expansion of the knowledge base in SE (Ireland, 2007). Over the years, it has seen, along with other journals, a very encouraging discourse around the concept that started as a strategy versus entrepreneurship debate and developed into an SE domain with its own identity. Recently, when the Web of Science database was searched for articles that contained the phrase "strategic entrepreneurship" in the text, 259 documents were identified that spanned various research topics, none of which received the sustained in-depth attention needed to advance knowledge in a meaningful fashion (Schröder, Tiberius, Bouncken, \& Kraus, 2021). As a result, there is growing concern that the SE concept remains "theoretically under-developed," so that it is unclear "what constitutes opportunity- and advantage-seeking activities" (Zhao, Ishihara, \& Jennings, 2020: 2).

While the debate around the definition, domain, and development of SE continues, we decided to mark the 20-year anniversary of Hitt et al.'s (2001) formal introduction of the SE concept with a handbook focused on chapters at the interface of strategy and entrepreneurship. Our thinking was that many scholars are interested in research at the intersection of strategy and entrepreneurship, without being distracted by ongoing discussions about the nature and evolution of the SE label. We wanted to understand what the important topics are at the intersection of strategy and entrepreneurship through the eyes (and minds) of scholars who are working in that space. Of course, we all know the specific topics we are interested in, but where is the collective wisdom of the academic community in terms of the topics that have already been researched and the topics that are worth studying going forward? With this in 
mind, we put out a call that asked scholars to submit "high-quality ambitious papers that summarize the research on particular topics within strategic entrepreneurship." We were interested in articles pertaining to either theoretical and/or methodological issues in particular areas at the strategy-entrepreneurship interface, or with the interface as a whole. Following Gartner (2014: 13), we asked prospective authors for chapters that help make "sense of the comprehensiveness" of their chosen topic area and "offer a depth of knowledge and insights" into the particular area they chose.

We were particularly happy to note that we received proposals from scholars pursuing a diverse set of studies within the SE domain. Over the last year and a half we worked with each team and were assisted by a very supportive set of reviewers. We completed a double blind review process that resulted in 10 chapters that we are delighted to present as a collection in the form of this Handbook. Those who read this Handbook cover to cover will find their interest in SE rejuvenated, and several new ideas for future research.

\section{CHAPTERS IN THIS HANDBOOK}

Nachiket Bhawe and Shaker Zahra are interested in the structural aspects of the knowledge networks that make up absorptive capacity (ACAP). Their chapter titled "Decomposing the knowledge structures of absorptive capacity" examines the knowledge content of ACAP and how it might affect innovation. Understanding this content can help in addressing the questions about ACAP's antecedents, its evolution, its multi-level nature, and its relationship with innovation. Bhawe and Zahra categorize the different knowledge structures that make up ACAP which enables them to show how ACAP emerges, evolves over time, and the mechanism by which it affects the magnitude and speed of innovation. Their discussion highlights micro foundations of the knowledge content of ACAP and how they can be used across multiple levels of analysis.

Susanne Bylund and Per Bylund define the firm as a vehicle for engaging in, or even a manifestation of, SE. Bylund and Bylund demonstrate that the economic firm is the embodiment of SE necessary for the implementation of entrepreneurial solutions - innovations. This chapter observes the process of the firm formation using a theory of the unhampered market that avoids problems of previous approaches and sheds new light on issues related to the essence of the firm from a Coasean perspective. Bylund and Bylund advance our understanding of the relationship between the markets, organization of the firm, and the function of management and leadership.

Florian Bayer and Christian Landau review 126 articles published within effectuation literature through the lens of SE in their chapter titled "Opportunity-seeking behaviors in strategic entrepreneurship: What do we know from the effectuation literature?" Bayer and Landau consider effectuation and causation as two contrasting perspectives towards entrepreneurial behaviors: causation rooted in the strategic management describing planning and prediction, and effectuation focusing on experimentation and flexibility in creating an entrepreneurial opportunity. This chapter 
demonstrates how SE and effectuation together advance our understanding of the nature of opportunity-seeking behavior in the entrepreneurial endeavor.

Riley Doyle, Kris Irwin, Josie Burks, Paul Drnevich, and C. E. Armstrong review, integrate, and examine the current state of academic research on incubators, accelerators, and other university-affiliated programs. Their chapter titled "Exploring new venture creation through incubators and accelerators: What value is created and who captures it? Implications for research, teaching, and practice" applies a value creation and capture logic perspective to discern the sources of different types of value created. Doyle et al. also delve into who captures the value created among key stakeholders of the ecosystems in which incubators and accelerators are located.

In their chapter, "Holistic view of strategic entrepreneurship's results: Estimating the implications for performance mean and variability," Oleksiy Osiyevskyy, Kanhaiya Kumar Sinha, Galina Shirokova, and Mehrsa Ehsani emphasize the need to go beyond traditional approaches to evaluating firm performance and analyzing the variance of the performance outcome. Osiyevskyy et al. contend that understanding the performance variability implications of entrepreneurial actions is very important for SE research, because it implies, on one hand, high risk (which is a major driver of business mortality), yet, on the other hand, enables enormously high returns (i.e., explains the possible high-growth outliers). The proposed approach is illustrated using an empirical example of assessing variance implications of two SE constructs - entrepreneurial orientation (an enabler of SE) and exploration (a crucial component of SE).

Diego Coraiola, Fernanda Tsujiguchi, and Roy Suddaby suggest that history can be a source of competitive advantage and foster entrepreneurial action. In their chapter titled "Historical cognition and strategic entrepreneurship," Coraiola et al. define history as cognition that involves perception of the past as an objective, interpretive, and imaginative reality. They suggest that reimagining history in multiple ways may inform alternative paths in the future for SE. Their cognitive perspective of history opens new avenues for future research directions in the SE field.

Betsy Campbell explores ethnomethodology and its potential value to SE in her chapter titled "Making strategic entrepreneurship visible: An ethnomethodology primer." Ethnomethodology and its traditions - including conversation analysis, embodied conversation analysis, membership category analysis, and workplace interaction - can reveal the endogenous ways that strategizing and entrepreneuring are accomplished in practice. Campbell explains what ethnomethodology is, how ethnomethodologically informed studies are done, and why such studies matter to SE.

In their chapter "The eye as a window to the soul: Entering the strategic entrepreneurial mind," Jef Naidoo, Ron Dulek, Elliot Miller Graves, and Yeong Hyun Hong introduce eye tracking as a new methodological approach to studying SE phenomena. The first part of the chapter examines eye movement behavior as a compelling physiological measure for studies in behavioral research. The second part observes the fundamental aspects of eye tracking - from a methodological and technological perspective - and its influence on research in a broad range of disciplines. Finally, 
Naidoo et al. conclude that the eye-tracking research approach is viable methodology to advance SE research and offers a potentially promising research agenda for SE inquiry.

Anne Pastwa and William Wales are interested in an important and often overlooked alternative data source for SE research, namely texts. Their chapter "New frontiers? Approaches to computerized text analysis in strategic entrepreneurship research" provide useful guidance to handling texts. Pastwa and Wales summarize several approaches used for textual data sources in SE research, focusing on the most popular and computer-assisted tools for text analyses. The chapter examines the relevance of these tools within the SE research domain. Finally, the authors illustrate the application of topic models with Latent Dirichlet Allocation for explaining the changes in entrepreneurial orientation of publicly listed companies over time.

In his chapter titled "Endogeneity in strategic entrepreneurship research," Brian Anderson focuses on endogeneity problems in SE studies, discussing common threats to causal inference. Anderson suggests an alternative approach to modeling in the SE field and outlines a Bayesian modeling approach to illustrate how entrepreneurship scholars may address multiple endogeneity problems. This chapter helps advance our understanding of the nuances in empirical modeling, providing an alternative to common econometric approaches that may not always be well suited for SE.

Our goal in putting together this Handbook was to provide new directions for future SE research. The rich variety of chapters offers a window into the comprehensiveness of the field and deep knowledge and insights into specific topic areas within SE. Based on our reading of the above chapters, we feel that the book covers fertile ground and represents the growth of the field. Among the chapters, there is evidence of new methods adopted by SE researchers (Anderson, Pastwa/Wales, and Osiyevskyy et al.), introduction of new topics such as effectuation (Bayer/Landau), psychological traits and cognitive approach-based research of SE (Naidoo et al. and Coraiola et al.), and an exploration of SE from a novel perspective (Bylund/ Bylund). The eclectic mix of chapters demonstrates the wide range across which SE as a domain has evolved. We believe this not only indicates the richness of the field, but also sets the stage for more researchers from other disciplines (e.g., finance, marketing, sustainability) to come forward and draw from and contribute towards this growing field. We hope this Research Handbook on Strategic Entrepreneurship will provide useful guidance for traveling new paths not only within the domain of SE research but also across other disciplines, based upon distinct theoretical foundations.

\section{NOTE}

1. Gupta (2020) observed that Venkatarman and Sarasvathy (2001)'s colorful description also points towards a crucial omission in strategy and entrepreneurship literatures: the missing Juliet. Scholars in strategy and entrepreneurship research have generally overlooked women (and femininity), resulting in their relative absence from the literature that comprises the knowledge base of both fields. 


\section{REFERENCES}

Acs, Z. J., \& Audretsch, D. B. (2003). Introduction to the handbook of entrepreneurship research. In Handbook of Entrepreneurship Research (pp. 3-20). Springer, Boston, MA.

Alvarez, S. A., \& Barney, J. B. (2001). How entrepreneurial firms can benefit from alliances with large partners. Academy of Management Perspectives, 15(1), 139-148.

Alvarez, S. A., \& Busenitz, L. W. (2001). The entrepreneurship of resource-based theory. Journal of Management, 27(6), 755-775.

Baker, T., \& Pollock, T. G. (2007). Making the marriage work: The benefits of strategy's takeover of entrepreneurship for strategic organization. Strategic Organization, 5(3), 297-312.

Bruton, G. D., Filatotchev, I., Si, S., \& Wright, M. (2013). Entrepreneurship and strategy in emerging economies. Strategic Entrepreneurship Journal, 7(3), 169-180.

Foss, N. J., \& Lyngsie, J. (2011). The emerging strategic entrepreneurship field: Origins, key tenets, and research gaps. In D. Hjorth (ed.), Handbook on Organisational Entrepreneurship (pp. 208-225), Edward Elgar, Cheltenham, UK and Northampton, MA, USA.

Gartner, W. (2014). Organizing entrepreneurship research. In A. Fayolle (ed.), Handbook of Research on Entrepreneurship: What We Know and What We Need to Know (pp. 13-22). Edward Elgar, Cheltenham, UK and Northampton, MA, USA.

Gupta, V. K. (2020). Great Minds in Entrepreneurship Research: Contributions, Critiques, and Conversations. Palgrave Macmillan, Cham.

Hambrick, D. C., \& Chen, M.-J. (2008). New academic fields as admittance-seeking social movements: The case of strategic management. Academy of Management Review, 33, $32-54$.

Hitt, M. A., Ireland, R. D., Camp, S. M., \& Sexton, D. L. (2001). Strategic entrepreneurship: Entrepreneurial strategies for wealth creation. Strategic Management Journal, 22(6-7), 479-491.

Hitt, M. A., Ireland, R. D., Sirmon, D. G., \& Trahms, C. A. (2011). Strategic entrepreneurship: Creating value for individuals, organizations, and society. Academy of Management Perspectives, 25(2), 57-75.

Ireland, R. D. (2007). Strategy vs. entrepreneurship. Strategic Entrepreneurship Journal, 1(1-2), 7-10.

Ireland, R. D., Hitt, M. A., \& Sirmon, D. G. (2003). A model of strategic entrepreneurship: The construct and its dimensions. Journal of Management, 29(6), 963-989.

Kraus, S., \& Kauranen, I. (2009). Strategic management and entrepreneurship: Friends or foes? International Journal of Business Science and Applied Management, 4(1), 37-50.

Kuratko, D. F., \& Audretsch, D. B. (2009). Strategic entrepreneurship: Exploring different perspectives of an emerging concept. Entrepreneurship Theory and Practice, 33(1), 1-17.

Lepak, D. P., Smith, K. G., \& Taylor, M. S. (2007). Value creation and value capture: A multilevel perspective. Academy of Management Review, 32(1), 180-194.

Meyer, G. D. (2009). Commentary: On the integration of strategic management and entrepreneurship: Views of a contrarian. Entrepreneurship Theory and Practice, 33(1), 341-351.

Pitelis, C. N. (2009). The co-evolution of organizational value capture, value creation and sustainable advantage. Organization Studies, 30(10), 1115-1139.

Schendel, D. E., \& Hofer, C. W. (1979). Introduction. In D. E. Schendel \& C. W. Hofer (eds.), A New View of Business Policy and Planning (pp. 1-22). Little, Brown and Company, Boston, MA.

Schröder, K., Tiberius, V., Bouncken, R. B., \& Kraus, S. (2021). Strategic entrepreneurship: Mapping a research field. International Journal of Entrepreneurial Behavior and Research, 27(3), 753-776.

Shane, S. (2012). Reflections on the 2010 AMR decade award: Delivering on the promise of entrepreneurship as a field of research. Academy of Management Review, 37(1), 10-20. 
Venkataraman, S., \& Sarasvathy, S. D. (2001). Strategy and entrepreneurship: Outlines of an untold story. In M. A. Hitt, R. E. Freeman, \& J. S. Harrison (eds.), The Blackwell Handbook of Strategic Management (pp. 655-674), Blackwell, Oxford.

Zabriskie, N. B., \& Huellmantel, A. B. (1991). Developing strategic thinking in senior management. Long Range Planning, 24(6), 25-32.

Zhao, E. Y., Ishihara, M., \& Jennings, P. D. (2020). Strategic entrepreneurship's dynamic tensions: Converging (diverging) effects of experience and networks on market entry timing and entrant performance. Journal of Business Venturing, 35(2), 105933. 